\title{
Study of aluminium oxide from high-alumina refractory ceramics by thermoluminescence
}

\author{
V CORRECHER, J GARCIA-GUINEA ${ }^{\dagger}$, R GONZALEZ-MARTIN $^{\dagger}$, E CRESPO-FEO $^{\dagger}$ and \\ D JIMENEZ-CORDERO ${ }^{\dagger}$
}

CIEMAT, Avda. Complutense 22, 28040 Madrid, Spain

${ }^{\dagger} \mathrm{MNCN}-\mathrm{CSIC}$, J. Gutierrez Abascal 2, 28006 Madrid, Spain

MS received 18 March 2008; revised 11 September 2008

\begin{abstract}
This work is focused on the study of the thermally stimulated blue emission of aluminium oxide $\left(\mathrm{Al}_{2} \mathrm{O}_{3}\right)$ that has been removed from twenty different high alumina-rich refractory bricks. The glow curve sensitivity of several alumina grains are defined by (i) a maximum centred at about $165^{\circ} \mathrm{C}$ that can be deconvoluted into two first order kinetic peaks at 157 and $177^{\circ} \mathrm{C}$ and (ii) a broad structure over $200-220^{\circ} \mathrm{C}$ that suggests a continuous trap distribution system. The isolated grains, analysed by means of $\mathrm{X}$-ray diffraction, are composed of $43 \%$ of alumina $\left(\mathrm{Al}_{2} \mathrm{O}_{3}\right), 22 \%$ of mullite $\left[72 \%\right.$ of $\mathrm{Al}_{2} \mathrm{O}_{3}$ and $28 \%$ of $\left.\mathrm{SiO}_{2}\right], 12 \%$ of leucite $\left(\mathrm{KAISi}_{2} \mathrm{O}_{6}\right)$ and $23 \%$ of sillimanite $\left[\mathrm{Al}_{2} \mathrm{O}_{3} \cdot \mathrm{SiO}_{2}\right]$. The sample characterization has been performed using $\mathrm{X}-\mathrm{ray}$ fluorescence and scanning electron microscopy.
\end{abstract}

Keywords. Ceramics; aluminium oxide; X-ray diffraction; scanning electron microscopy; thermoluminescence.

\section{Introduction}

The studies performed on the thermomechanical properties and the microstructure of synthetic alumina $\left(\mathrm{Al}_{2} \mathrm{O}_{3}\right)$ have been widely investigated (Mitra et al 1992). In this sense, synthetic $\mathrm{Al}_{2} \mathrm{O}_{3}$ obtained by Verneuil (Manuilov and Peshev 1992), Bayer process (Mahadevan and Ramachandran 1996) or Czochralski (Baughman and Lefever 1975) method, doped with different types and proportion of impurities, have been of great interest not only for industrial purposes, but also to be employed in the field of thermoluminescence (TL) dosimetry (Molnar et al 1999; Tokumoto et al 2006).

The TL emission of ceramic materials and mineral phases concerns inter-disciplinary research areas involving both solid-state physics and radiation physics with wideranging applications in geological (Bailey 2004) and archaeological (Feathers 2003) dating, retrospective assessment of irradiation dose (Pandya et al 2000; Bailiff et al 2005) and detection of irradiated food (Correcher et al 1998). These ubiquitous materials appear as a reasonable alternative to the conventional dosimetric systems since they have good sensitivity to radiation, a linear response with the increase of dose and reasonable stability of the luminescence signal with the time of storage (Correcher et al 2004). This behaviour has been used for the dose

*Author for correspondence (v.correcher@ciemat.es) evaluation in several retrospective dosimetry studies based on luminescence techniques usually performed on quartz removed from common ceramic materials. Such methodology has been successfully applied with traditional red clay bricks and tiles to estimate the cumulative external gamma dose arising from the radiation of Chernobyl accident (Bailiff et al 2005) and tentatively in cements (Gartia et al 1995). However, one can consider the possibility of using alternative ceramic materials for dosimetric purposes, e.g. high-alumina rich refractory bricks since they (i) could exhibit luminescence properties similar to the well-known synthetic alumina $(\alpha$ $\mathrm{Al}_{2} \mathrm{O}_{3}$ ) and (ii) have been annealed and, consequently, the thermoluminescence (TL) clock has been properly set to zero. These materials that have been seldom investigated for such purposes are characterized by the lack of quartz owing to a chemical reaction that produces mullite $\left(\mathrm{Al}_{2} \mathrm{O}_{3}+\mathrm{SiO}_{2} \rightarrow \mathrm{Al}_{2} \mathrm{SiO}_{5}\right)$ (Tripathi et al 2003). On this basis, it could be expected that the TL behaviour of synthetic alumina grown under controlled conditions does not differ too much from aluminium oxide extracted from the alumina rich refractory bricks. The crystal structure of alumina, which is found in nature as corundum, sapphire and ruby, consists of a slightly distorted hexagonal $\mathrm{O}^{2-}$ ion sub-lattice $\left(\mathrm{C}_{2}\right.$ symmetry) with $\mathrm{Al}^{3+}$ ions in two out of three octahedral interstices $\left(\mathrm{O}_{\mathrm{h}}\right.$ symmetry). The unit cell symmetry is $\mathrm{C}_{3}$ (Tokumoto et al 2006). Two electrons giving rise to a neutral $\mathrm{F}$ centre occupy each oxygen vacancy centre. When $\mathrm{F}^{+}$centre is formed (i.e. occupancy 
of one instead of two electrons), compensators are required to preserve the charge balance of the lattice (Molnar et al 1999). These charge compensators can induce (i) the formation of defects in the structure, (ii) point defects, including aluminium-associated trapped hole centres and (iii) oxygen vacancies. All of them are directly related to the intensity and shape of the TL glow emission.

This paper reports on the characterization of TL of $\mathrm{Al}_{2} \mathrm{O}_{3}$ detected in the blue transmission band $320-480 \mathrm{~nm}$ from grains removed from high-alumina refractory bricks produced in an early 20th century metallurgical furnace in Hiendelaencina (Guadalajara, Spain) under reducing conditions. The samples were previously studied by means of X-ray diffraction (XRD), scanning electron microscopy (SEM) and X-ray fluorescence (XRF) to determine the structure and chemical content of impurities.

\section{Experimental}

All the brick samples were taken at a height of $1 \mathrm{~m}$ above ground level. Once in the laboratory, the twenty selected refractory bricks were cut using a water-lubricated diamond blade to produce different slices (figure 1) under red light to avoid the release of the trapped electrons from the metastable sites into hole centres by the environmental light irradiation. The white crystalline mineral grains, directly removed from the slices using mechanical crushing and sieving procedures, were analysed by means of XRD using the powder method in a Siemens D-5000 automated diffractometer with $\mathrm{CuK}_{\alpha}$ radiation. The XRD measurements were performed by step scanning from $2^{\circ}$

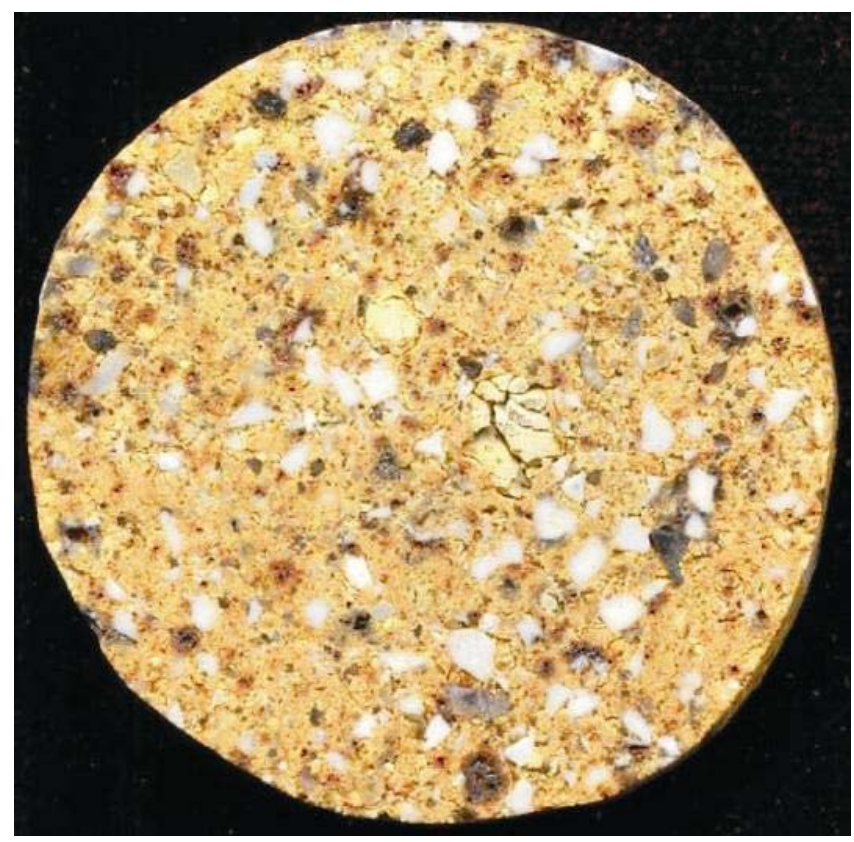

Figure 1. Slice of one of the twenty analysed refractory bricks cut using a water-lubricated diamond blade. to $64^{\circ} 2 \theta$ in steps of $0.020^{\circ}$, and a counting time of $6 \mathrm{~s}$ per step. The chemical composition of these white grains has been analysed by XRF. A pressed pill of powdered samples weighing $8 \mathrm{~g}$ was chemically analysed by wavelength XRF to determine its global chemical composition in major and trace elements at the $\mu \mathrm{g} \cdot \mathrm{g}^{-1}$ level. Both, qualitative and quantitative measurements were performed in an XRF-spectrometer PW-1404 Philips, equipped with an X-ray tube of Sc-Mo, a scintillation crystal detector Harshaw type $\mathrm{NaI}(\mathrm{Tl})$ and operating at $80 \mathrm{~kW}$ and $30 \mathrm{~mA}$. SEM assays were done using a Zeiss DSM-90 (40 kV electron microscope with a resolution of $70 \AA$ ). The microanalysis detector was a $\mathrm{Si}-\mathrm{Li}$ model, using a Tractor Northern Z2 computer. Sample metallization were made using gold vapour in a vacuum (50 $\AA$ of gold cover).

The TL measurements were performed using an automated Risø TL system model TL DA-12 (Botter-Jensen and Duller 1992), this reader has an EMI 9635 QA photomultiplier and the emission was observed through a blue filter (FIB002 Melles-Griot) with transmission in the $320-480 \mathrm{~nm}$ range; FWHM is $80 \pm 16 \mathrm{~nm}$ and peak transmittance is $60 \%$. It has a ${ }^{90} \mathrm{Sr} /{ }^{90} \mathrm{Y}$ beta source with a dose rate of $0.020 \mathrm{~Gy} \mathrm{~s}^{-1}$ calibrated against a ${ }^{60} \mathrm{Co}$ photon source in a secondary standards laboratory (Correcher and Delgado 1998). The TL measurements were performed at a heating rate of $5^{\circ} \mathrm{C} \cdot \mathrm{s}^{-1}$ from room temperature to $500^{\circ} \mathrm{C}$ in a $\mathrm{N}_{2}$ atmosphere. A set of four aliquots of $5 \pm 0.1 \mathrm{mg}$ each of the sample was used for each measurement. The sample was carefully powdered $(90-125 \mu \mathrm{m})$ with a pestle and mortar to avoid triboluminescence (Garcia-Guinea and Correcher 2000). The incandescent background was subtracted from the TL data. The kinetic parameters of the TL glow peaks were estimated by means of a computerized curve-fitting program based on first order kinetics, glow curve analysis (GCA), developed by Delgado and Ros (2001) that allows the identification of the TL glow curve structure.

\section{Results and discussion}

\subsection{Sample characterization}

According to the XRD study, the main composition of the white grains removed from the whole refractory bricks is: $43 \%$ of corundum $\left(\mathrm{Al}_{2} \mathrm{O}_{3}\right), 22 \%$ of mullite $\left[72 \%\right.$ of $\mathrm{Al}_{2} \mathrm{O}_{3}$ and $28 \%$ of $\mathrm{SiO}_{2}$ ], $12 \%$ of leucite $\left(\mathrm{KAlSi}_{2} \mathrm{O}_{6}\right)$ and $23 \%$ of sillimanite $\left[\mathrm{Al}_{2} \mathrm{O}_{3} \cdot \mathrm{SiO}_{2}\right]$ (figure 2). The isolated grains of white pure alumina $\left[\mathrm{Al}_{2} \mathrm{O}_{3}\right]$, embedded in a mullite matrix, allow us to speculate that the starting raw material to produce the bricks, is mainly made of a mixture of previously ground pure alumina sand together with kaolinite $\left[\mathrm{Al}_{2} \mathrm{Si}_{2} \mathrm{O}_{5}(\mathrm{OH})_{4}\right]$. These bricks were probably processed by moulding under high pressure and sintering under high temperature, with features like large heat accumulating capacity and small creep rate. Such a mixture, melted during the refractory brick firing, gave rise to sillimanite 


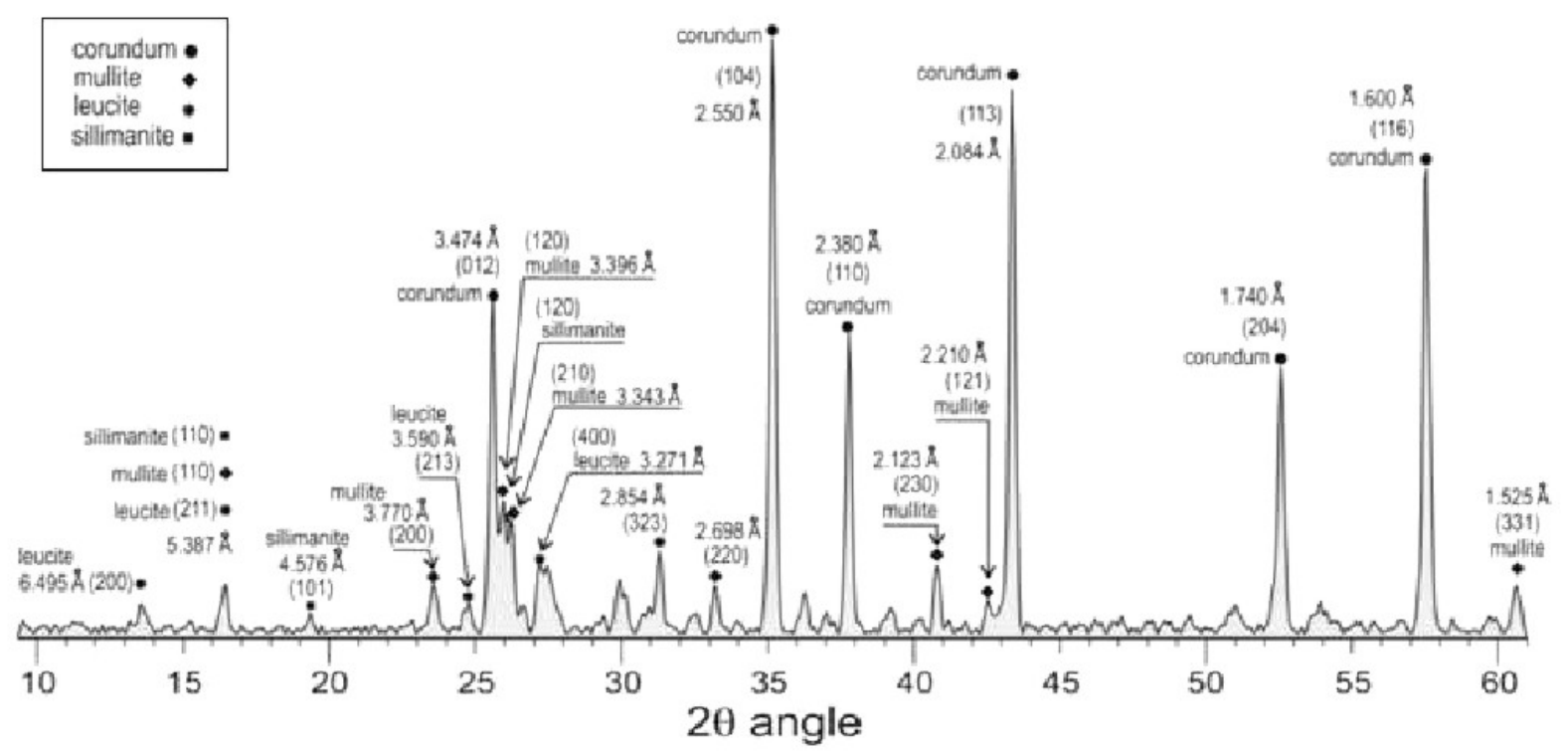

Figure 2. X-ray diffractogram performed on a white opaque grain. It is possible to distinguish $43 \%$ of corundum $\left(\mathrm{Al}_{2} \mathrm{O}_{3}\right), 22 \%$ of mullite $\left[72 \%\right.$ of $\mathrm{Al}_{2} \mathrm{O}_{3}$ and $28 \%$ of $\mathrm{SiO}_{2}$ ], $12 \%$ of leucite $\left(\mathrm{KAlSi}_{2} \mathrm{O}_{6}\right)$ and $23 \%$ of sillimanite $\left[\mathrm{Al}_{2} \mathrm{O}_{3} \cdot \mathrm{SiO}_{2}\right]$.

and leucite. All the detected components could act as natural phosphors for dosimetric purposes since they exhibit luminescence emission (Wojtowicz and Lempicki 1989; Yarovoi and Veksler 1998; Garcia-Guinea et al 2001a).

The SEM observations indicate the presence of a fine layer of $\mathrm{ZrO}_{2}$ on the surface of several alumina grains (figure 3 ). It probably stems from zircon $\left[\mathrm{ZrSiO}_{4}\right]$ rich natural mixed sands usually employed in the brick production. It is quite common to find small amounts of different natural radioactive impurities ( $U$ and $T h$ ) in zircon compounds that are the suppliers of radiation energy necessary to induce TL emission.

The bulk chemical analysis of the alumina samples, performed under XRF, indicates the presence of $\mathrm{Fe}$ (2120 ppm), Ti (1580 ppm), K (1190 ppm), Zr (862 ppm), $\mathrm{Ca}$ (680 ppm), Na (550 ppm), Ba (386 ppm), Mg (320 ppm), $\mathrm{Zn}(236 \mathrm{ppm}), \mathrm{Sr}(227 \mathrm{ppm}), \mathrm{Pb}(169 \mathrm{ppm})$ and $\mathrm{Cu}$ $(138 \mathrm{ppm})$. These impurities, especially trivalent ions $\left(\mathrm{Fe}^{3+}\right)$, substitute the $\mathrm{Al}$ in the whole framework and all valence bonds are satisfied. However, when divalent cations $\left(\mathrm{Mg}^{2+}, \mathrm{Ca}^{2+}, \mathrm{Sr}^{2+}\right)$ substitute the $\mathrm{Al}$, interstitial monovalent ions $\left(\mathrm{Na}^{+}, \mathrm{K}^{+}\right)$are required to preserve charge balance. The impurities that are incorporated into the alumina structure, yield intrinsic defects in the crystal lattice and will modify not only the relative intensity of component bands, but also changes in the wavelength response, quantum efficiency, temperature position in the TL signal and/or even induce new luminescence signals. Such behaviour is a consequence of the lattice distortion due to the size of the incorporated impurities. We could not detect the radioactive impurities, using XRF, mainly due to the low concentration of the aforementioned acti- nides (lower than detection limit of the equipment) that, according to previous studies performed on natural zircons, should be circa 6 ppb (Correcher et al 2003a).

\subsection{Thermally stimulated luminescence}

The natural TL glow curves show the appearance of two peaks at about 157 and $177^{\circ} \mathrm{C}$, which is characteristic of materials containing $\mathrm{Al}-\mathrm{O}$ bonds, and (above $200-220^{\circ} \mathrm{C}$ ) a very complex structure consisting of a broad distribution typically observed in several natural materials (such as diaspore, an aluminium oxo-hydroxide $-\alpha-\mathrm{AlOOH}-$ ) (Correcher et al 2003b). The TL physical trapping parameters for the curve (trap depth in $\mathrm{eV}, E$, frequency factor in $\mathrm{s}^{-1}, s$, intensity of the maximum in arbitrary units, a.u., $I_{\max }$, peak position in ${ }^{\circ} \mathrm{C}, T_{\max }$, and figure of merit in percentage (FOM), parameter that indicates the goodness of the fitting) were estimated using the GCA program. All the analysed parameters were refined to a confidence limit of $95 \%$ accuracy. As shown in figure 4 , the dashed lines correspond to the calculated fitted first order kinetics peaks, which make up the calculated fitted solid line. This encircling line is directly compared with the experimental dotted line.

The low-temperature peak (at $157^{\circ} \mathrm{C}$ ) has also been detected in synthetic doped alumina $\left(\alpha-\mathrm{Al}_{2} \mathrm{O}_{3}\right)$ (Molnar et al 1999). This maximum could be due to radiative decay $\mathrm{F}$ centres produced by the reduction of this material that leads to the formation of oxygen vacancies ( $F$ type centres) that would act as emission centres. According to Molnar et al (1999), the trap responsible of this maximum could be associated with $\mathrm{Al}^{3+}$ vacancies linked to 
charge compensators, for example, oxygen vacancies giving rise to a complex defect (i.e. an electron trap). In an oxidizing atmosphere the oxygen vacancy concentration is reduced and, consequently, should decrease the recombination centres. This is probably the reason of the low level TL intensity observed in our samples. Assuming that the trap responsible for the $157^{\circ} \mathrm{C}$ peak in alumina is an electron trap, one could analyse the TL glow peak, as a good approach; in terms of first order kinetics (i.e. the intensity of the TL signal is proportional to the concentration of thermally released charges).

As observed in natural diaspore, the high-temperature maximum peaking at $177^{\circ} \mathrm{C}$ can be linked to a discrete trap structure (Garcia-Guinea et al 2001b, 2005). This peak has also been detected in $\mathrm{Al}_{2} \mathrm{O}_{3}$ : $\mathrm{C}$ that is usually employed for the estimation of environmental doses (Guissi et al 1999; Yukihara et al 2003) and in natural diaspore (Correcher et al 2003b). It happens despite (i) this TL emission stems from aluminium oxide instead of diaspore, which possesses a different structure and (ii) its origin formed initially in oxidizing atmosphere and subsequently maintained in depleted oxygen atmosphere. Following the similar reasoning given for diaspore and synthetic alumina, this peak could be considered mainly associated with the presence of divalent impurities (e.g. $\mathrm{Mg}^{2+}$ ) that replace $\mathrm{Al}^{3+}$; it supposes the generation of oxygen vacancies, which can act as recombination centres. Therefore, it could be accepted that the intensity of this emission is proportional to the concentration of traps given by the presence of different types or the concentration of divalent impurities. Both the value of activation energy and the frequency factor $(s)$, that informs the probability per second for the release of a trapped charge

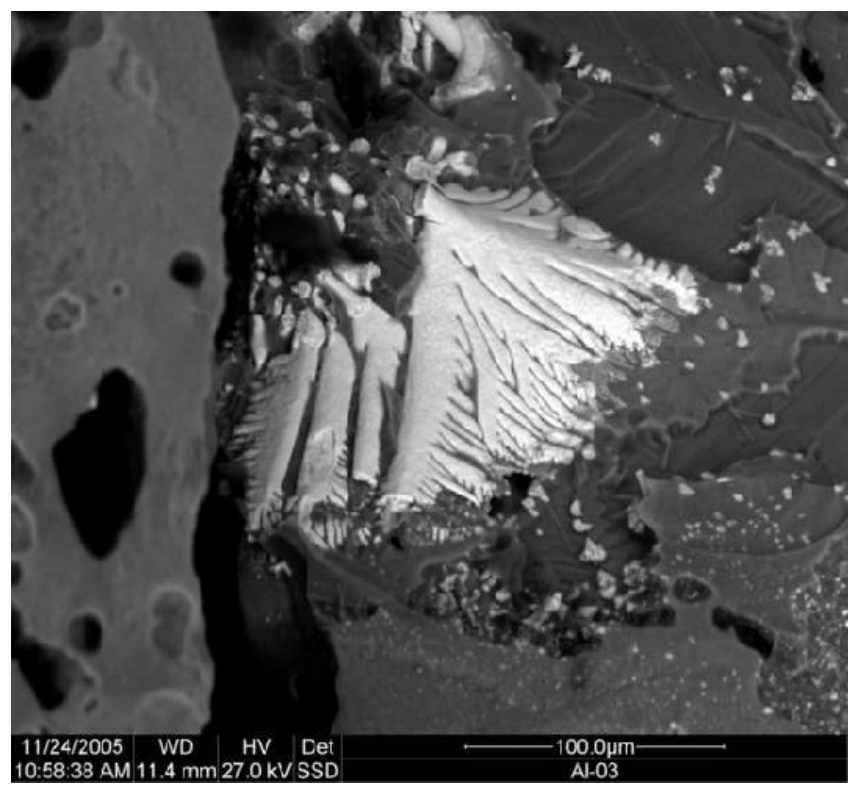

Figure 3. Detail of a SEM picture where $\mathrm{ZrO}_{2}$ is observed on the surface of some alumina grains. carrier of the experimental TL spectra, are well correlated with the theoretical calculations made by Guissi et al (1999) and Correcher et al (2003b) corresponding to alpha alumina and diaspore, respectively (table 1). The value of the FOM is lower than $4 \%$ that indicates an acceptable good fitting (Balian and Eddy 1977). The ratio of the TL intensities of both deconvoluted peaks, separated by $20^{\circ} \mathrm{C}$, is $\sim 2: 1$. Assuming the aforementioned interpretation, one can speculate that these samples possess a double number of electron trap centres (due to Al-vacancies compensated with oxygen vacancies) than Al-vacancies compensated with $\mathrm{Mg}$ impurities and oxygen vacancies that should act as recombination centres. On this basis, this ratio could be linked to two stages during the formation of the sample: (i) A process that should be associated with the synthesis of the corundum generated in oxidizing atmosphere during the sintering of the refractory brick. This process is related to a local disorder in the material and therefore, with the low-temperature TL signal. (ii) A low temperature treatment in reducing conditions produced during the working period of the bricks in the kiln that promote other defects producing the $177^{\circ} \mathrm{C}$ TL signal.

The low intensity broad structure over $200-220^{\circ} \mathrm{C}$ suggests a continuous trap distribution system as described in diaspore by Garcia-Guinea et al (2001b, 2005). It should correspond to de-hydroxylation mechanisms and chromophore oxidation that could help to explain the high temperature UV-blue emissions mainly due to the presence of leucite, sillimanite and mullite (figure 2). This thermolabile high temperature TL broad band of blue emission exhibits the typical multi-order kinetics behaviour involving continuous processes of electron trapping-detrapping. These thermal phenomena of TL are

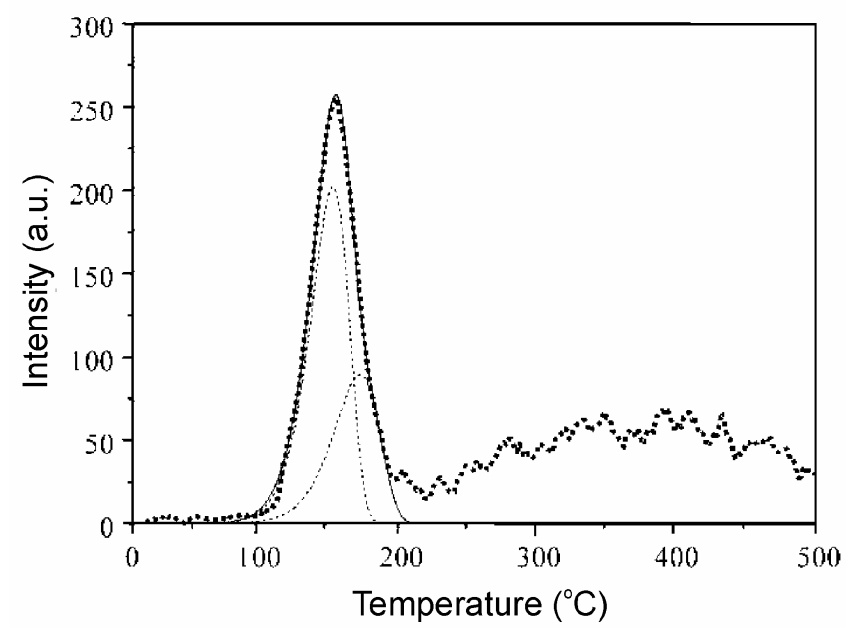

Figure 4. Natural TL glow curve of alumina removed from the refractory brick. The well-defined peak at lower temperature can be deconvoluted into two components (peaked at 157 and $177^{\circ} \mathrm{C}$ ) assuming first order kinetics. 
Table 1. Kinetic parameters resulting from the analysis of the natural TL glow curves of alumina removed from the refractory brick assuming first order kinetics. The value of the FOM (figure of merit) is $3 \cdot 1 \%$.

\begin{tabular}{lccccc}
\hline Peak & $E(\mathrm{eV})$ & $S\left(\mathrm{~s}^{-1}\right)$ & $I_{\max }($ a.u. $)$ & $T_{\max }\left({ }^{\circ} \mathrm{C}\right)$ & Area $(\%)$ \\
\hline 1 & $1.11 \pm 0.02$ & $3.71 \times 10^{14}$ & $202 \pm 52$ & $157 \pm 4$ & 65.41 \\
2 & $1.01 \pm 0.02$ & $5.94 \times 10^{12}$ & $89 \pm 21$ & $177 \pm 6$ & 34.59 \\
\hline
\end{tabular}

synchronous with the de-hydroxylation process, which carry out consecutive breaking linking of bonds of Al-O, $\mathrm{Fe}-\mathrm{O}, \mathrm{Al}-\mathrm{OH}$ and $\mathrm{Fe}-\mathrm{OH}$ including the formation of hydrolyzed ions such as $\mathrm{Al}\left(\mathrm{H}_{2} \mathrm{O}\right)_{6}^{3+}$, and $\mathrm{Fe}\left(\mathrm{H}_{2} \mathrm{O}\right)_{6}^{3+}$ and redox reactions; whereas there are some other non hydrolyzable chains that remain unchangeable (Guissi et al 1999; Garcia-Guinea et al 2005). In addition, the intrinsic structure of these specimens (leucite, sillimanite and mullite) includes twinning planes, antiphase domain boundaries, exsolution borders, modulations, etc. These natural superlattices complexity give many different points of egress for the alkali ions during thermal treatments; many distinct sets of dynamic TL traps are produced which could explain the difficulty in parametrizing the TL glow curves of the alkali aluminosilicates.

\section{Conclusions}

Grains of aluminium oxide removed from high alumina rich refractory bricks from an old and abandoned 20th century metallurgical furnace characterized by X-ray diffraction indicates that it is composed of $43 \%$ of alumina $\left(\mathrm{Al}_{2} \mathrm{O}_{3}\right), 22 \%$ of mullite $\left[72 \%\right.$ of $\mathrm{Al}_{2} \mathrm{O}_{3}$ and $28 \%$ of $\mathrm{SiO}_{2}$, $12 \%$ of leucite $\left(\mathrm{KAlSi}_{2} \mathrm{O}_{6}\right)$ and $23 \%$ of sillimanite $\left[\mathrm{Al}_{2} \mathrm{O}_{3} \cdot \mathrm{SiO}_{2}\right]$. The blue TL emission of these $\mathrm{Al}_{2} \mathrm{O}_{3}$ grains exhibits two peaks at about 157 and $177^{\circ} \mathrm{C}$, which is characteristic of materials containing $\mathrm{Al}-\mathrm{O}$ bonds, and could be respectively linked to (i) Al-vacancies compensated with oxygen vacancies and (ii) Al-vacancies compensated with $\mathrm{Mg}$ impurities and oxygen vacancies that should act as recombination centres. At higher temperatures (above $200-220^{\circ} \mathrm{C}$ ) it is possible to distinguish a very complex structure consisting of a wide distribution that could be associated with a continuous trap distribution due to the presence of leucite, sillimanite and mullite. The studied luminescent properties of this material show that it could be a potentially valid radiation environmental dosimeter to be applied in the field of geological dating or retrospective dosimetry as an alternative or complement of quartz, usually employed for these purposes.

\section{Acknowledgements}

This work has been supported by the CICYT (FIS200761823) and Comunidad Autonoma de Madrid (CAM)
MATERNAS (S-0505/MAT/0094) projects. Authors thank Dr Delgado and Dr Gomez-Ros for the GCA program.

\section{References}

Bailey R M 2004 Radiat. Meas. 38299

Bailiff I K et al 2005 Health Phys. 89233

Balian H G and Eddy N W 1977 Nucl. Instrum. Meth. 145389

Baughman R J and Lefever R A 1975 Mater. Res. Bull. 10607

Botter-Jensen L and Duller G A T 1992 Nucl. Track Radiat. Meas. 20549

Correcher V and Delgado A 1998 Radiat. Meas. 29411

Correcher V, Muniz J L and Gomez-Ros J M 1998 J. Sci. Food Agric. 76149

Correcher V, Robredo L M, Valle-Fuentes F J, Lopez-Arce P and Garcia-Guinea J 2003a Bol. Soc. Esp. Ceram. 42369

Correcher V, Garcia-Guinea J and Valle-Fuentes F J 2003b Geophys. Res. Lett. 301949

Correcher V, Gomez-Ros J M and Garcia-Guinea J 2004 Radiat. Meas. 38689

Delgado A and Ros J M G 2001 Radiat. Prot. Dosim. 96127

Feathers J K 2003 Meas. Sci. Technol. 141493

Garcia-Guinea J and Correcher V 2000 Spectrosc. Lett. 33103

Garcia-Guinea J, Correcher V and Rodriguez-Badiola E 2001a Analyst 126911

Garcia-Guinea J, Rubio J, Correcher V and Valle-Fuentes F J 2001b Radiat. Meas. 33653

Garcia-Guinea J, Correcher V, Rubio J and Valle-Fuentes F J 2005 J. Phys. Chem. Solids 661220

Gartia R K, Ingotombi S and Singh S D B 1995 Mater. Sci. 18107

Guissi S, Iacconi P, Bindi R and Lapraz D 1999 Radiat. Prot. Dosim. 84247

Mahadevan H and Ramachandran T R 1996 Bull. Mater. Sci. 19905

Manuilov N and Peshev P 1992 Mater. Res. Bull. 27805

Mitra B L, Biswas N C and Aggarwal P S 1992 Bull. Mater. Sci. 15131

Molnar G, Papin E, Grosseau P, Guilhot B, Borossay J, Benabdesselam M, Iacconi P and Lapraz D 1999 Radiat. Prot. Dosim. 84253

Pandya A, Vaijapurkar S G and Bhatnagar P K 2000 Bull. Mater. Sci. 23155

Tokumoto Y, Sato Y, Yamamoto T, Shibata N and Ikuhara Y 2006 J. Mater. Sci. 412553

Tripathi H S, Mukherjee B, Das S K, Ghosh A and Banerjee G 2003 Bull. Mater. Sci. 26217

Wojtowicz A J and Lempicki A 1989 Phys. Rev. B39 8695

Yarovoi P N and Veksler A S 1998 Inorg. Mater. 341149

Yukihara E G, Whitley V H, Polf J C, Klein D M, McKeever S W S, Akselrod A E and Akselrod M S 2003 Radiat. Meas. 37627 